\title{
Human capital in the system of sustainable development goals: significance and prospects
}

\author{
Ekaterina Ugnich $^{1, *}$, Alexander Chernokozov $^{2}$, and Maxim Ugnich ${ }^{1}$ \\ ${ }^{1}$ Don State Technical University, Gagarin sq., 38, Rostov-on-Don, 344000, Russia \\ ${ }^{2}$ All-Russian State University of Justice, 2 k.1, Azovskaya str., Moscow, 117638, Russia
}

\begin{abstract}
The concept of human capital through the prism of international economic relations and the problem of achieving sustainable development goals are considered in this paper. The value of HCI in the system of assessing the prospects for the development of human capital at the global level is shown. The characteristics of the relationship between HCI components and sustainable development goals are given. The analysis of the ranking of the countries of the world by the HCI is given. The features of the BRICS countries are revealed: despite the high potential for the development of human capital, it is not always used effectively, which is reflected in the implementation of the program to achieve sustainable development goals. It is shown that in modern conditions, the concept of sustainable development of human capital is of decisive methodological importance. It is based on the need to maintain a balance of various spheres of human life, reflecting, in fact, the quality of his life. The COVID-19 pandemic has strengthened the importance of anchoring the principles of this concept at the global level.
\end{abstract}

\section{Introduction}

The dynamic development of scientific and technological progress, the complexity and variability of socio-economic relations, global uncertainty form a reality of the modern world that is unique in complexity and variability. In these conditions of the development of modern civilization, the relevance of the concept of sustainable development for the world and national economy increases. Sustainable development implies a constant growth in the wellbeing of people in a quality environment. Sustainable development factors are classified in three areas: natural environment, economy and society. The principles of sustainable development were developed by the UN Commission in 1987. In 2015, the UN General Assembly resolution adopted the "Transforming our world: the 2030 Agenda for Sustainable Development", which includes 17 goals and 169 objectives (resolution A/RES/70/1 [1]). At the same time, within the framework of achieving sustainable development, the importance of ensuring a high quality of life for current and future generations is emphasized. Thus, the transition to sustainable development poses serious challenges for all components of the socio-economic structure of society, and a person here appears as a key subject of sustainable development [2].

\footnotetext{
*Corresponding author: ugnich77@mail.ru
} 
On the other hand, the COVID-19 pandemic has plunged the global economy into the deepest recession in eighty years [3]. It has dealt a direct blow to human capital around the world, having a negative impact on both education and human health. The possibility and pace of recovery from the pandemic will largely depend on the volume of investments in health care and education, i.e. in human capital. In this regard, it is relevant to study the state and place of human capital of various states in the system of sustainable development goals.

\section{Materials and methods}

The study is based on a systematic approach [4] to understanding national socio-economic systems, the key element of which is human capital. To understand the role and place of human capital in the implementation of sustainable development goals in the context of the national economy, its systematic assessment is required. The assessment should be informative enough to identify the instruments and mechanisms of public policy that would be more conducive to the development of human capital and sustainable development. At the same time, it is necessary to emphasize the importance of its non-financial assessment in view of the fact that it allows more fully assessing the current state and trends of change, and not measuring only the financial value [5]. Among the variety of approaches to assessing human capital, one can single out the cost-based, income-based, market-based approaches $[6,7]$, as well as the "indicator" approach based on non-financial assessment [8]. The "indicator" approach is used by the World Bank to rank countries by indices of human development and human capital. It focuses on non-financial comparative characteristics (mainly of the human capital of countries). The use of the human capital index for the analysis of national socio-economic systems is most suitable for the purposes of this study.

The study of human capital in the BRICS countries is of particular interest, since these are countries with a dynamically developing economy, they are home to $42 \%$ of the world's population, they account for more than $27 \%$ of the gross world product and about $20 \%$ of international investment [9]. This paper focuses on the prospects for the development of human capital in the BRICS countries for sustainable development.

The empirical basis of the study was made up of key macroeconomic indicators and the human capital index of different countries of the world, presented by The World Bank Group.

\section{Results and Discussion}

Although interest in the study of human resources and their impact on performance has arisen for a long time, the very concept of "human capital" was first proposed by J. Minser in 1958 [10]. The founders of the theory of human capital are considered to be T. Schultz [11] and G. Becker [12]. In formulating the definition of human capital, they noted the productive nature of investment in a person, providing a significant and relatively longer lasting effect.

The concept of human capital is reflected in the implementation of policy measures in a number of countries. Since the 1960s, in many countries of the Organization for Economic Cooperation and Development (OECD), the state began to play an active role in the development of education. Becker G. [13] argued that investment in human capital in the form of educational opportunities has played a key role in accelerating economic growth since the 1960s. Thus, the importance of the concept of human capital was emphasized at the state level back in the twentieth century.

However, there is currently no single concept of human capital. At the same time, all those who study this aspect emphasize that the "core" of human capital is the knowledge and skills of its bearer - man [14]. 
The variety of approaches to understanding the essence and, consequently, the methods of assessing human capital is partly caused by the fact that the complexity and integrating nature of human capital allows considering it at several levels: from mega to micro ones. This is how global, national, regional human capital, enterprise and individual human capital are distinguished. At each level of aggregation, human capital is divided into different, relatively isolated elements that characterize different aspects of the personality or the association of people.

Within this work, we will limit ourselves to the study of national human capital. From this position, the definition of The World Bank is of interest, which considers human capital as a set of knowledge, professional qualities, experience that individuals possess and that make them "economically productive". Human capital can be increased by investing in education, health care, and vocational training.

In order to characterize the state of national human capital, it is necessary to have an idea of its assessment [15]. In this case, the assessment should reflect the comparative characteristics of the countries. These conditions are met by the indicator approach, namely the Human Capital Index presented by The World Bank for ranking countries.

The Human Capital Index (HCI) was developed by The World Bank in 2018 to measure the contribution of health and education to the productivity of the next generation of workers. The HCI value can range from 0 to 1 , where 1 means maximum potential. The HCI compares the level of human capital that a child born in a given country can expect to have by age of 18 years old, taking into account the risk associated with inadequate quality of education and health care. It also allows comparing the future productivity of such a worker in comparison with the productivity of labor in an ideal situation and estimate the economic losses associated with the slowdown in GDP growth caused by this factor.

The HCI is intended to complement the Human Development Index (formerly the Human Potential Development Index), which has been used since 1990, which focused on living standards, taking into account national income per capita at purchasing power parity. The analysis of HCI assessment is more consistent with the objectives of this study, since it focuses on human capital, i.e. the health, knowledge and skills accumulated by people during their life.

In addition, the constituent components of HCI (survival, schooling and health) are directly related to at least three UN Global Sustainable Development Goals (SDGs), which should be achieved by the countries of the world by 2030 :

- the indicator of the reduction in mortality of children under five years of age, included in the HCI, links with SDG 3.2 (reduction of neonatal mortality to 12 or less cases per 1000 live births, and mortality of kids under 5 years old - to 25 or less cases per 1000 live births);

- the indicator of the length of schooling in relation to the quality of the gained knowledge, included in the HCI, is aimed at supporting SDG 4.1 (ensuring, among other things, the possibility to obtain equitable and quality primary and secondary education);

- the HCI includes the rate of adult survival and prevalence of stunting in children that reflect the achievement of SDG 3.4 (reducing premature mortality from noncommunicable diseases by one third through prevention, treatment and maintenance of mental health and well-being) and SDG 2.2 (ending all forms of malnutrition by 2030).

Thus, the HCI aims to draw attention to a diverse range of measures in different sectors of the economy that can contribute to the growth of human capital and accelerate the achievement of the SDGs.

In 2018, using the HCI, 157 countries of the world were assessed and ranked (visually, the results are shown in Fig. 1). Singapore got the highest HCI (0.88) and Chad the lowest one (0.29). It is noteworthy that the BRICS countries have a fairly large spread of HCI values. So, the HCI in Russia is 0.73 (34th place), China - 0.67 (46th place), Brazil - 0.56 (81st place), India - 0.44 (115th place), South Africa - 0.41 (126 a place). 


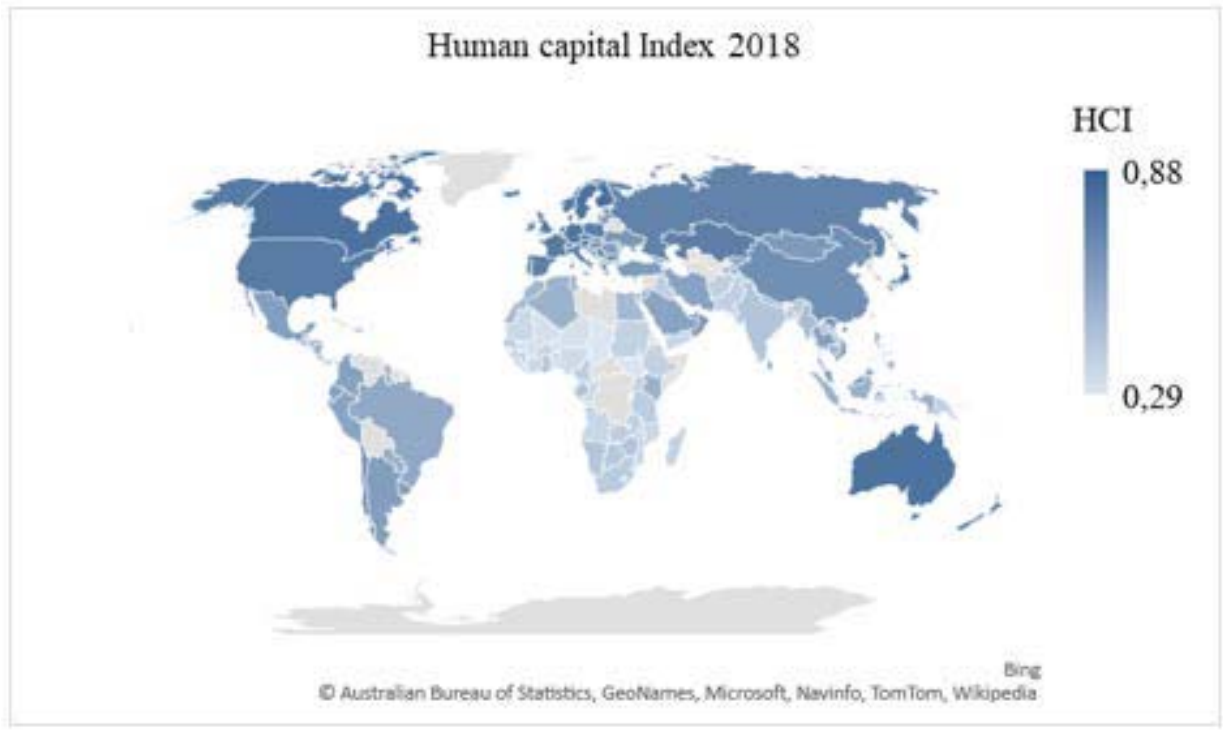

Fig. 1. Ranking of countries by the HCI on the world map, 2018.

While the HCI provides insight into the benefits of different countries in terms of human capital development, it does not always reflect the degree to which human capital is linked to economic growth. Nevertheless, the existence of this relationship was established in the works of P. Romer, devoted to the model of endogenous growth [16]. The literature notes that the differences between countries in terms of GDP by 10-30\% are caused by differences in the development of human capital [17]. The influence of human capital on economic growth is explained by the fact [18] that it contributes to the creation and dissemination of new products and technologies. In addition, the owners of "high" quality human capital are capable of more complex work, and the latter creates more added value per unit of time than the work of an unskilled worker.

The high degree of relationship between human capital and GDP per capita (as a comparable indicator of economic growth) is also indicated by the value of the Pearson coefficient calculated on the basis of 2018 data for the above 157 countries. The obtained correlation coefficient between HCI and GDP per capita was 0.86 , which allows concluding about their close positive relationship.

Figure 2 illustrates the relationship between HCI and GDP per capita. For example, the countries with the highest HCI (Singapore, South Korea, Japan, Ireland, Finland) are located in the upper right part (upper cluster), and countries with the lowest HCI (Cote d'Ivoire, Liberia, Niger, Mali, Chad) - in the lower left part (lower cluster). It is noteworthy that the BRICS countries have an intermediate value in Figure 2, but their location here indicates that human capital in these countries has unrealized potential, which is expressed in a relatively low value of GDP per capita with the available HCI particularly in comparison with the countries of the upper cluster. It should be noted that despite a not very large gap in HCI values, for example, Russia (0.73) and OECD countries on average (0.76), the gap in GDP per capita seems to be quite significant (almost three times GDP per capita in OECD countries is on average higher than in Russia).

The presence of the unrealized potential of human capital in the BRICS countries is also indirectly confirm the calculation of the correlation coefficient (Pearson) between public spending on the formation of human capital (education) and the volume of GDP per capita. So, if in the BRICS countries it was 0.09 , then in the OECD countries its value is 0.42 . In other words, the relationship between government spending on human capital formation and 
GDP per capita in the BRICS countries is weaker than in the developed OECD countries. Of course, this conclusion is preliminary and requires further research. It should also be borne in mind that the costs of human capital formation are formed not only at the expense of the state budget [19], but also at the expense of private funds (households and corporations). However, in the BRICS countries, the ratio of expenditures on education is still more distributed in favor of state funds (for example, in Russia, the share of these expenditures is $84 \%)$.

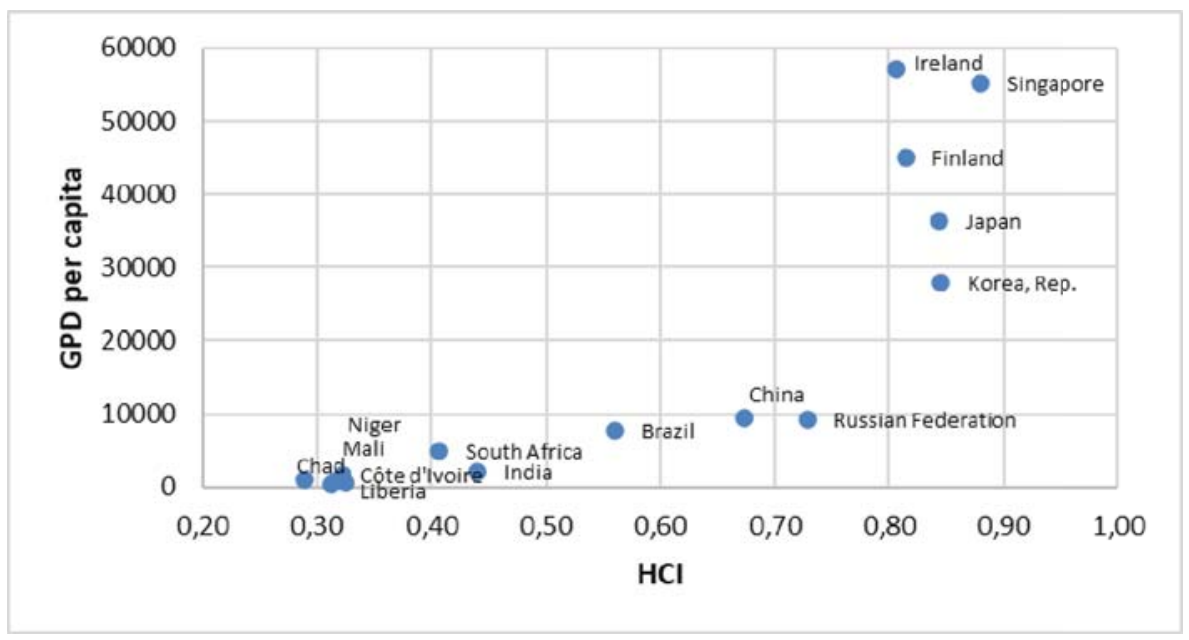

Fig. 2. Ranking of countries by the HCI on the world map.

Still, the reason for the lower efficiency of state policy in the field of human capital in the BRICS countries can be explained by the fact that its attention is mainly focused on the field of human capital formation. However, in order to achieve economic growth and sustainable development, it is also important how human capital is used. Of course, increasing the efficiency of using human capital should not only be the basis of state policy for the BRICS countries, but also enshrined in the global agenda of world development.

At the same time, for the development of society, this type of human capital is of particular interest, the bearer of which is a subject that implements a creative function in the process of social production, associated with the creation and improvement of fundamentally new algorithms of activity and is able to set local and strategic goals. It is this type of human capital that cannot be replaced in the process of robotization. Moreover, this type is the true human capital, which has its own qualities of a full-fledged subject, which cannot be separated from their bearer.

In our opinion, for the purposes of state policy aimed at achieving a balance between the formation and development of human capital, attention should be paid to the concept of sustainable development of human capital. This concept is appropriate for managing it at both the micro and macro levels [2]. The concept of sustainable development of human capital emphasizes a fair attitude towards its bearer, the need to take care of its development, health and well-being, supports environmentally friendly organizational practices, and is focused on work-life balance [20].

According to researchers, the balance between work and personal life is a balance of time, a balance of obligations and a balance of an individual's satisfaction with his role in the process of performing work and outside it [21]. The negative consequences of the imbalance between the analyzed spheres of life affect not only specific individuals. A temporary inability to satisfy specific groups of needs related to personal, social and leisure life will affect the functioning of the individual in the process of work, which is caused by the 
interdependence and complementarity of the spheres of human activity ("work-life"). Ultimately, this will affect the creation of added value and the ability to achieve economic growth in general. Therefore, the concept of sustainable development of human capital, based on the balance of various spheres of a person's life, reflecting, in fact, the quality of his life, should be taken as the basis for the formation of state policy.

In addition, the COVID-19 pandemic has currently affected the state of human capital. The impact of the pandemic has been felt not only by the younger generation receiving education, but also by the older generation, who account for most of the deaths. In addition to such consequences as deteriorating health status of the population, disruption of the life processes of society and an increase in unemployment, a pandemic can negatively affect the productivity of the human capital of people who are currently participants in the labor market. In addition, remote work, prevalent during the ongoing COVID-19 pandemic, could disrupt the balance of professional and social roles. In this case, there is a high risk of "stretching" the working time and disrupting the rhythm of work and rest of a person [22].

Thus, ensuring a balance between work and personal life should be enshrined in the principles of state policy in the field of human development, aimed at the productive use of human resources and the achievement of competitiveness through the development of intangible assets, increasing fertility, gender equality and improving the quality of life. It should be borne in mind that the implementation of state policy aimed at improving the state of human capital [23] may take a sufficient amount of time. In the short term, it is possible to effectively increase the return on human capital only if its bearers have a job. Consequently, human resource policies should also aim to address employment issues. It should also be remembered that a healthier and more educated population will stimulate economic growth in the long term [24].

\section{Conclusion}

The study of the comparative advantages of countries, caused by the peculiarities of the state of human capital, confirmed its organic relationship with the processes of achieving economic growth and sustainable development. Despite the fact that education and health care are declared as priorities within the framework of the state policy of many countries of the world, including the BRICS countries, it becomes obvious that it is necessary to pay attention not only to the mechanism of human capital formation, but also to its use. Here, it is of great importance to consolidate the principles of the concept of sustainable development of human capital at the state level. It is based on the need to maintain a balance of various spheres of human life, reflecting, in fact, the quality of his life. The COVID-19 pandemic, which has worsened the state of human capital around the world, increases the need to consolidate this concept at the national and global level. Besides, regular monitoring of the state of human capital is needed today. The HCI can serve as one of the key indicators for monitoring, as an indicator that allows effectively planning and achieving the UN sustainable development goals.

\section{References}

1. Resolution adopted by the General Assembly on 25 September 2015. Transforming our world: the 2030 Agenda for Sustainable Development. UN Doc. A/RES/70/1 (2015)

2. P. Ferreira, C. Gabriel, S. Faria, P. Rodrigues, M. Sousa Pereira, Sustainability 12, 2743 (2020)

3. Global Economic Prospects: Pandemic, Recession: The Global Economy in Crisis (World Bank, 2020) 
4. E.G. Popkova, V.I. Tinyakova, World Applied Sciences Journal 24(4), 467-475 (2013)

5. J. Chen, Z. Zhu, Yu. Xie, Journal of Intellectual Capital 5(1), 195-212 (2004)

6. V.L. Zakovorotny, M.B. Flek, E.A. Ugnich, International Journal of Economic Perspectives 10(4), 371-375 (2016)

7. E.G. Flamholtz, Human Resource Accounting (Jossey-Bass Publ., N.Y., 1985)

8. A. Kraay, Methodology for a World Bank Human Capital Index. Policy Research Working Papers (The World Bank, 2018) doi:10.1596/1813-9450-8593

9. BRICS Joint Statistical Publication 2018. Statistics South Africa. Pretoria: Statistics South Africa (2018)

10. J. Mincer, Journal of Political Economy 66(4), 281-302 (1958)

11. T. Shultz, Human Capital in the International Encyclopedia of the Social Sciences (Macmillan, New York, 1968)

12. G. Becker, Human Capital (Columbia University Press, New York, 1964)

13. G. Becker, Proceedings of the American Philosophical Society 136(1), 85-92 (1992)

14. S. Makarov, E. Ugnich, Foresight Russia 9(1), 56-67 (2015)

15. A.M. Kumykov, M.Z. Shogenov, N.A. Chemaev, F.Z. Shogenova, N.N. Reshetnikova, Espacios 38(57), 28 (2017)

16. P.M. Romer, Journal of Political Economy 98.5(2), 71-102 (1990)

17. C.-T. Hsieh, P.J. Klenow, American Economic Journal: Macroeconomics 2(1), 207-23 (2010).

18. Ya. Kuzminov, P. Sorokin, I. Froumin, Foresight and STI Governance 13(2), 19-41 (2019) doi: 10.17323/2500-2597.2019.2.19.41

19. S.S. Zmiyak, E.A. Ugnich, P.M. Taranov, Lecture Notes in Networks and Systems 73, 567-576 (2020) doi: 10.1007/978-3-030-15160-7_57

20. R.L. Kahn, D.M. Wolfe, R. Quinn, J.D. Snoek, R.A. Rosenthal, Organizational Stress: Studies in Role Conflict and Ambiguity (John Wiley \& Sons, New York, 1964)

21. J.H. Greenhaus, K.M. Collins, J.D. Show, J. Vocat. Behav. 63, 510-531 (2003)

22. K. Mikołajczyk, Sustainability 13, 697 (2021) doi: 10.3390/su13020697

23. Y. Shafieva, O. Kovalenkova, S. Tekucheva, IOP Conference Series: Materials Science and Engineering 918(1), 012049 (2020)

24. P.M. Taranov, M.A. Taranov, Lecture Notes in Networks and Systems, 133, 597-609 (2021) doi: 10.1007/978-3-030-47458-4_69 